\title{
Resistencias cotidianas a la privatización de recursos naturales en Portugal a inicios del siglo XX: el ejemplo de la caza furtiva en la región del Alentejo ${ }^{1}$.
}

\author{
Jesús Ángel Redondo Cardeñoso ${ }^{2}$
}

\begin{abstract}
RESUMEN
El artículo analiza la caza furtiva en las comunidades rurales portuguesas de inicios del siglo XX. Para ello, tomamos como marco de estudio la región portuguesa del Alentejo entre los años 1910 y 1917. El texto se divide en cuatro partes: primero, se hace una breve descripción socioeconómica de la región de estudio; segundo, se estudia la legislación sobre caza; tercero, se analiza la extensión de la caza ilegal en la región a través de la información recogida en periódicos regionales y documentación del gobierno civil; $\mathrm{y}$, cuarto, se profundiza en el análisis de la naturaleza de la caza furtiva por medio de documentación judicial de ámbito local referentes al municipio de Arraiolos. Nuestro objetivo es mostrar cómo la caza furtiva fue una práctica generalizada que fue utilizada por las clases populares de la región para resistirse ante una legislación que privatizaba y restringía el libre aprovechamiento de recursos naturales esenciales para sus economías domésticas de subsistencia.
\end{abstract}

Palavras-Chave: Caza furtiva, resistencias cotidianas, campesinos, comunidades rurales, Alentejo.

\footnotetext{
${ }^{1}$ Este trabajo ha sido financiado por fondos de la Fundação para a Ciência e a Tecnologia (FCT) y por el Fondo Europeo de Desarrollo Regional (FEDER) a través del COMPETE 2020-Programa Operacional Competitividad e Internacionalización (POCI) y PT 2020, en el ámbito del proyecto UID/HIS00057/2019.

2 Investigador postdoctoral de la Universidad de Valladolid (España) e Investigador colaborador del Centro Interdisciplinar de História, Culturas e Sociedades (CIDEHUS) de la Universidad de Évora (Portugal). Correo electrónico: jesus.redondo.cardenoso@uva.es.
} 


\title{
INTRODUCCIÓN
}

\begin{abstract}
"[...] quando deviam ser pouco mais ou menos nove horas, encontraram doze individuos todos munidos de espingardas e que andavam caçando [...] o guarda dirigiu-se aos caçadores e perguntou-lhes se queriam sahir da herdade e que seria isso o melhor, ao que os mesmos respoderam "que estavam resolvidos a sahir, que ainda procuraram o dono da herdade para lhe preguntar se podiam caçar, mas constou-lhes que elle não estava lá, e, como já tinham ouvido dizer que se caçava n'outros coutos e, por isso, julgavam que havia liberdade para caçar em toda a parte, tinham entrado, mas visto que assim não era, iam-se embora" ${ }^{3}$
\end{abstract}

El texto que acabamos de transcribir forma parte de un proceso judicial abierto por el tribunal comarcal de Arraiolos (distrito de Évora, región del Alentejo) contra doce vecinos del municipio (concelho) por cazar ilegalmente en el paraje conocido como Herdade da Mata. Concretamente, los hechos ocurrieron el 15 de octubre de 1910, apenas diez días más tarde de que triunfara la revolución en Lisboa que instauró la República en Portugal. Ése no fue un hecho aislado. La incertidumbre que siguió a la (inesperada) proclamación de la República favoreció la propagación de rumores de todo tipo. Uno de ellos decía que se había suprimido el régimen forestal, una legislación que, como veremos más detalladamente, acotaba el libre ejercicio de la caza en la mayor parte de terrenos y montes particulares del país. La propagación de tal noticia motivó que "grandes grupos de cazadores invad[i]e[ra]n, con sus numerosas jaurías, las propiedades particulares sometidas al aludido régimen"4. Es lo que sucedió con "un grupo de 94 cazadores armados, naturales de los concelhos de Estremoz y Borba" (distrito de Évora), quienes penetraron sin permiso en la heredad de Serra d'Ayres, en la pedanía de Santo Aleixo (concelho de Monforte, distrito de Portalegre), lo que obligó a intervenir a los regimientos de caballería $\mathrm{n}^{\circ} 3$ y $10^{5}$. Algo similar ocurrió con otro grupo de "cazadores de Borba y Orada" quienes, pocos días después, intentaron cazar sin autorización en el coto de la casa Bragança sito en Vila Viçosa (distrito de Évora), ante lo cual el gobernador civil requirió la intervención del

\footnotetext{
${ }^{3}$ Proceso n. ${ }^{\circ} 2327,15$ de octubre de 1910, Fondo del Tribunal de Comarca de Arraiolos, Procesos criminales, Legajo n. ${ }^{\circ} 67$, Archivo Distrital de Évora (en adelante, $A D E$ ).

${ }^{4}$ A Folha do Sul, 22 de octubre de 1910, 2.

${ }^{5}$ Oficio n. ${ }^{\circ}$ 280, 19 de octubre de 1910; Oficio n. ${ }^{0} 285,20$ de octubre de 1910; y Oficio n. ${ }^{\circ}$ 291, 22 de octubre de 1910, Fondo Gobierno Civil, E/Correspondencia, Copiadores/3a Repartición, Caja 14-A, Libro n. ${ }^{\circ} 14, \mathrm{ADE}$.
} 
propio regimiento de caballería $\mathrm{n}^{\circ} 10^{6}$. Muy seguramente, todos estos individuos, igual que ocurrió con nuestros doce protagonistas de Arraiolos, "habían oído decir que se cazaba en los otros cotos y, por eso, juzgaban que había libertad para cazar en todas partes".

No obstante, este tipo de conflictos protagonizados por grupos de cazadores furtivos no se limitaron a los convulsos episodios que se produjeron en Portugal en octubre de 1910. Sin ir más lejos, dos años más tarde, en noviembre de 1912, el administrador del concelho de Arraiolos solicitó el envío de patrullas de la Guardia Nacional Republicana (GNR) "para prestarle auxilio [...] evitando que un grupo de cazadores invadan una propiedad sujeta al régimen forestal" ${ }^{17}$. En definitiva, todos los ejemplos que acabamos de ver son una clara muestra de que, en la sociedad rural portuguesa de principios del siglo XX, existía un conflicto latente por el usufructo de la caza en montes y campos privados entre los propietarios (apoyados por las autoridades y las fuerzas del orden público) y los campesinos que vivían en los alrededores.

Éste no es un tema nuevo en la historiografía. Ya en su día, E. P. Thompson realizó un estudio donde analizó la caza furtiva en la Inglaterra del siglo XVIII a raíz de la promulgación de la Black Act en 1723, una ley que no sólo castigaba a quien cazara y/o robara animales, sino también a aquellos individuos que simplemente portaran un arma dentro de los bosques y montes ${ }^{8}$. Del mismo modo, otros autores anglosajones han visto en la caza furtiva una expresión de resistencia campesina. Por ejemplo, E. Hobsbawm y G. Rudé señalaron cómo la caza furtiva (junto al robo o el contrabando) podía ser "una afirmación primitiva de justicia social y de rebelión", tal y como sucedió durante la "campaña silenciosa, amarga y vengativa de caza furtiva, incendios y terror rural" que siguió a las revueltas del capitán Swing de $1830^{9}$. Por su parte, James C. Scott retomó el ejemplo del cazador furtivo inglés del siglo XVIII que estudiara su

${ }^{6}$ Oficio n. ${ }^{\circ}$ 311, 29 de octubre de 1910, Fondo Gobierno Civil, E/Correspondencia, Copiadores/3a Repartición, Caja 14-A, Libro n. ${ }^{\circ}$ 14, ADE.

${ }^{7}$ Oficio n. ${ }^{\circ}$ 626, 30 de noviembre de 1912, Fondo Gobierno Civil, E/Correspondencia, Copiadores/3a Repartición, Caja n. ${ }^{0}$ 14, Libro n. ${ }^{\circ}$ 15, ADE.

${ }^{8}$ Edward P. Thompson, Whigs and hunters: the origin of the Black Act (London: Allen Lane, 1975).

${ }^{9}$ Eric J. Hobsbawm y George Rudé, Revolución industrial y revuelta agraria. El Capitán Swing (Madrid: Siglo XXI, 1985), 18 y 80. 
maestro Thompson para ilustrar las "formas cotidianas de rebelión campesina" pesar del éxito en el ámbito anglosajón, el estudio de la caza furtiva no ha tenido el mismo eco en la Historia Social portuguesa, donde apenas encontramos algunos contados estudios que se limitan a certificar que la caza fue una práctica generalizada en la sociedad rural tradicional portuguesa y, específicamente, alentejana ${ }^{11}$.

En este artículo queremos profundizar en el análisis de la caza furtiva como una expresión ilustrativa de la conflictividad social originada en las sociedades rurales por la disputa de los recursos naturales. Para ello tomaremos como ejemplo de estudio el Portugal de inicios del siglo XX y, en concreto, el distrito de Évora, dentro de la región del Alentejo (véase mapa 1), entre los años 1910 y 1917. La razón de tomar como marco geográfico de estudio el Alentejo, es que ésta fue una de las regiones portuguesas donde, según diversos autores, tuvo mayor incidencia un tipo de delincuencia rural que incluía pequeñas transgresiones como el vagabundeo (vadiagem), el robo y hurto de frutos del campo o la invasión de pastos... todos los cuales pueden ser consideradas como acciones soterradas de resistencia y rebeldía rural $^{12}$. Por su parte, hemos tomado como marco cronológico el primer septenio de la I República portuguesa, años 1910-1917, por dos razones. La primera, porque, como enseguida veremos, con la promulgación de la ley de caza de 1913, los primeros gobiernos republicanos culminaron el proceso legislativo iniciado a inicios del siglo XX que buscaba perseguir el libre ejercicio de la caza. Y la segunda, porque para el análisis de los delitos juzgados en el tribunal comarcal de Arraiolos, sólo hemos podido consultar la serie completa de esos años.

El texto se estructura en cuatro partes: en la primera describiremos brevemente las características socioeconómicas de la región de estudio a inicios del siglo XX; en la segunda realizaremos un análisis de la legislación sobre caza promulgada en Portugal desde finales del siglo XIX hasta inicios del siglo XX; en la tercera examinaremos la importancia cuantitativa y cualitativa que tuvo la práctica de

\footnotetext{
10 James C. Scott, "Formas cotidianas de rebelión campesina", Historia Social, 28 (2018): 13-39.

11 Mário do Carmo, O problema da caça no Alentejo (1901-1975). Atitudes, expectativas e tensões sociais no distrito de Beja (Lisboa: Mário do Carmo, 2000), 21-29; Ana Fonseca, O Montado no Alentejo (Século XV a XVIII) (Lisboa: Colibri, 2004), 112-114.

12 José Cutileiro, Ricos e pobres no Alentejo (Uma sociedade rural portuguesa) (Lisboa: Libraria Sá da Costa Editora, 1977); José P. Pereira, "As lutas sociais dos trabalhadores alentejanos: do banditismo à greve", Análise Social, 61-62 (1980): 135-156.
} 
la caza furtiva en el distrito de Évora mediante el análisis de la prensa regional y documentación del Gobierno Civil; y, en la cuarta, descenderemos a un nivel de análisis local para rastrear las causas y orígenes de la caza furtiva que se ejerció en el concelho de Arraiolos, utilizando para ello los procesos que por este delito abrió el tribunal de comarca de la villa.

\section{BREVE DESCRIPCIÓN SOCIOECONÓMICA DE LA REGIÓN DEL ALENTEJO A INICIOS DEL SIGLO XX}

El Alentejo, con más de 30.000 kilómetros cuadrados, es la región más grande de Portugal y se extiende por la mayor parte de la mitad sur del país. Tradicionalmente, la región se ha dividido en cuatro subregiones: Alto Alentejo, Alentejo Central, Bajo Alentejo y Alentejo Litoral, las cuales, a grandes rasgos, se corresponden con los actuales distritos de Portalegre, Évora y Beja, y buena parte del de Setúbal.

Una de las principales características de la región era (y es) su marcado carácter rural. Por un lado, porque la mayor parte de los centros de población son villas y aldeas que, como mucho, contaban con unos pocos millares de habitantes. Es más, las únicas poblaciones que a inicios del siglo XX se podían considerar como centros urbanos eran las capitales de distrito (Portalegre, Beja y Évora), cada una de las cuales apenas superaba los 20.000 habitantes $^{13}$. Por otro lado, porque la economía de la región se basaba en la agricultura, especialmente de cultivos cerealeros, los cuales se expandieron por el sur del país desde finales del siglo XIX favorecidos por las leyes proteccionistas de 1889 y 1899 ${ }^{14}$. La única excepción a esta economía predominantemente agrícola era industria de transformación de corcho y fabricación de tapones en centros como Évora o Vendas Novas ${ }^{15}$, al amparo de la cual surgió un destacado proletariado industrial (corticeiros).

La actividad agrícola de la región estaba profundamente condicionada por la acusada desigualdad en la distribución de la propiedad de la tierra. Por ejemplo, en

\footnotetext{
${ }^{13}$ Censo da População de Portugal no 1. ${ }^{\circ}$ de Dezembro de 1911 (Lisboa: Imprensa Nacional, 1913).

14 Helder A. Fonseca, O Alentejo no século XIX. Economía e atitudes económicas (Lisboa: Imprensa Nacional Casa da Moeda, 1996).

${ }^{15}$ Ana M. Cardoso, "A indústria no distrito de Évora, 1836-90", Análise Social, 112-113 (1991): 571-573; Fonseca, O Alentejo no século XIX, $52-72$.
} 
1910, el área media de las explotaciones agrarias en el distrito de Évora era de más de 10.000 hectáreas, en el distrito de Beja era de 7.400 y en el de Portalegre de 5.800; todas ellas, cifras infinitamente superiores a las de las explotaciones del norte del país, cuya área media no superaban la hectárea ${ }^{16}$. Como consecuencia de este acusado latifundismo, la mayor parte de la sociedad alentejana eran trabajadores rurales que obtenían su sustento vendiendo diariamente su fuerza de trabajo a los grandes propietarios $^{17}$. La dependencia diaria a un salario (bajo) provocaba que, cuando se paralizaban las labores agrícolas durante las lluvias y fríos de otoño e invierno, la mayor parte de los trabajadores rurales alentejanos quedaran en situación de desempleo, originando graves crisis de trabajo y algunas protestas sociales, como fueron las manifestaciones de trabajadores desempleados ${ }^{18}$. Con todo, durante los primeros años del siglo XX, estos trabajadores impulsaron una muy destacada movilización obrera que cuestionó las tradicionales relaciones sociolaborales del Alentejo, lo que inevitablemente derivó en notables conflictos sociales durante los primeros meses de la I República, entre los que destacaron las huelgas agrarias de 1911 y $1912^{19}$.

No obstante, las relaciones laborales no fueron el único foco de conflictividad social en la región durante aquellos años, sino que también causaron numerosos conflictos otros asuntos, como fue el usufructo y aprovechamiento de recursos naturales, que es el objeto de estudio de este texto.

\footnotetext{
${ }^{16}$ Vasco P. Valente, O poder e o povo. A revolução de 1910 (Lisboa: Moares, 1982), 47.

17 Manuel V. Cabral, "Situação do operariado nas vésperas da implantação da República", Análise Social, 112-113 (1977): 425-426.

18 José Cutileiro, Ricos e pobres, 89-105; José P. Pereira, Conflitos sociais nos campos do sul de Portugal (Mem Martins: Publicações EuropaAmérica, 1983), 28-31; Jesús Ángel Redondo Cardeñoso, "Movilización y conflictos campesinos durante la crisis de la Monarquía y la instauración de la I República en Portugal: el Alentejo Central entre 1908 y 1914", Historia Social, 90 (2018): 27.

${ }_{19}$ Pereira, Conflitos sociais nos campos, 21-76; Ana P. de Brito Pereira, "As greves rurais de 1911-1912: uma leitura através da imprensa", Análise Social, 77-78-79 (1983): 477-511; Redondo Cardeñoso, "Movilización y conflictos campesinos".
} 


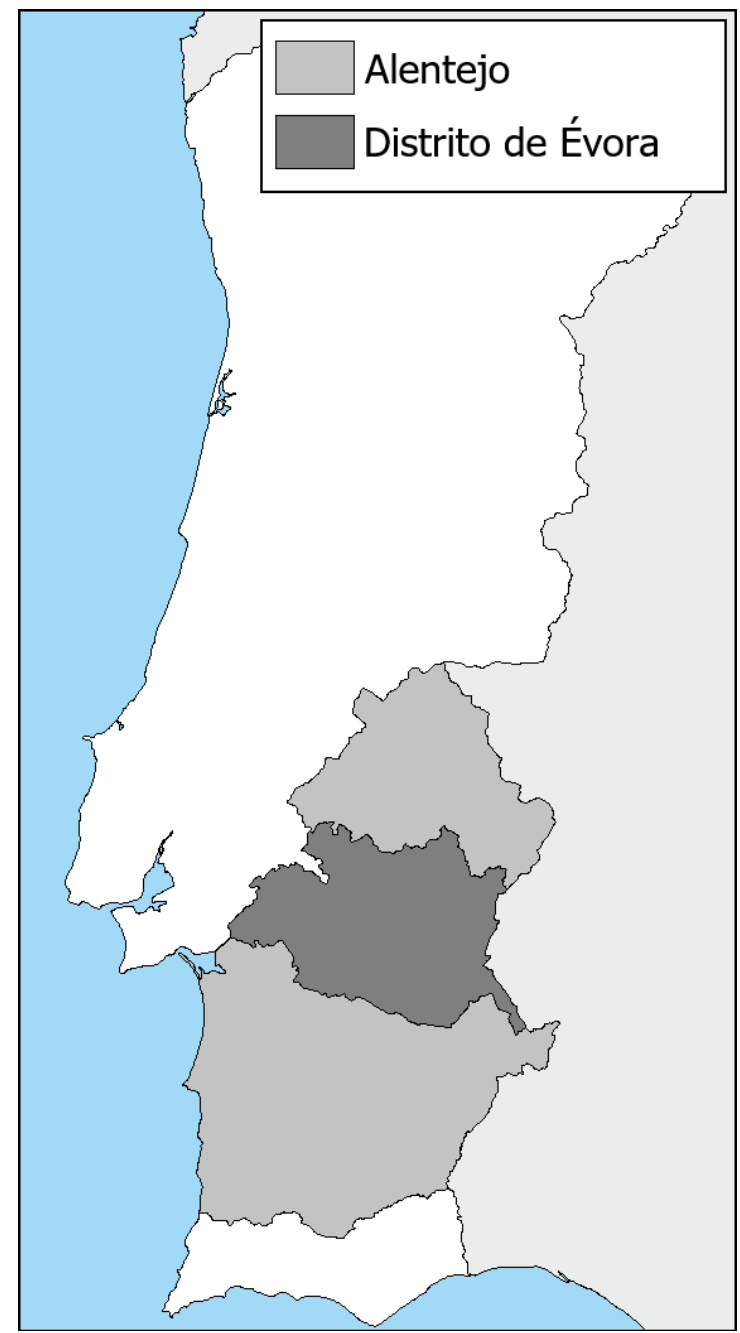

Mapa 1. Localización de la región del Alentejo y del distrito de Évora FUENTE: Elaboración propia

\section{La legislación sobre la CAZa en Portugal: De los Códigos de Posturas Municipales A LA LEY DE CAZA DE 1913}

Una de las principales muestras de la importancia de la caza furtiva en las comunidades rurales portuguesas de finales del siglo XIX e inicios del XX, fue la enorme batería legislativa que promulgaron las autoridades para intentar controlar esta práctica. El objetivo último de toda esta legislación fue aumentar las zonas de caza privadas y, a su vez, reducir, hasta su práctica desaparición, los terrenos donde se podía ejercer la caza de forma libre, perjudicando con ello a los cazadores de las 
clases más pobres que no podían pagar las diferentes cuotas e impuestos que se exigieron para poder cazar de forma legal ${ }^{20}$.

A finales del siglo XIX, el control legal sobre el ejercicio de la caza quedó en manos de las Cámaras Municipales, quienes legislaron al respecto mediante los Códigos de Ordenanzas (Posturas) Municipales. En este sentido, por ejemplo, el Código de Posturas da Cámara Municipal do Concelho d'Arrayollos ${ }^{21}$, aprobado en 1892 , dedicó al control de la caza la Sección primera del Título "Policía Rural", que principalmente establecía dos medidas las cuales limitaban el ejercicio de la caza desde un punto de vista territorial y temporal: prohibía cazar en terrenos cultivados y fuera de los períodos de veda (entre marzo y junio). El Código de 1892 fue reformado (una única vez) en 1897, con el objeto único de añadir una nueva postura que restringía, aún más, la práctica de la caza en el concelho. De este modo, el artículo $6^{\circ}$ de la postura añadida prohibió "cazar en emboscadas con o sin ave reclamo, así como también el uso de cualquier otros reclamos, redes, lazos, hilos, ratoneras o cualquier otro tipo de trampa, bajo la pena establecida en el artículo 254. ${ }^{\circ}$ del código penal". Esto es, prohibía explícitamente el tipo de caza que mayoritariamente ejercían aquéllos individuos que no podían comprar una escopeta o pagar una licencia de armas. Por su parte, el artículo $9^{\circ}$ de la nueva postura definió que un individuo estaba cazando cuando "fuera encontrado equipado de escopeta, u otros pertrechos apropiados para el ejercicio de la caza". Es decir que, del mismo modo que establecía la Black Act inglesa de 1723, la ley permitía penar no sólo a quien fuera sorprendido en el mismo acto de cazar, sino también a quien simplemente portara un arma en terrenos acotados para la libre caza. Por último, el artículo $11^{\circ}$ penaba a "todo individuo que fuera encontrado, en tiempo de veda, vendiendo, comprando, conduciendo, o transportando caza de cualquier especie" con 1000 réis de multa por pieza. Esta disposición suponía perseguir no sólo al cazador furtivo, sino también a aquellas personas que comúnmente, como veremos, se dedicaban a vender piezas

${ }^{20}$ Carmo, O problema da caça no Alentejo, 51.

${ }^{21}$ Código de Posturas da Cámara Municipal do Concelho d'Arrayollos (Évora: Typ. Economica de José d'Oliveira, 1892). 
cazadas ilegalmente para obtener unos ingresos complementarios para sus precarias economías domésticas.

No fue hasta el siglo XX cuando el estado portugués comenzó a asumir las competencias para regular el ejercicio de la caza. Para ello creó, como ya hemos apuntado, el régimen forestal a través de decretos promulgados en 1901, 1903 y $1905^{22}$. En resumen, estos tres decretos permitieron crear reservas privadas de caza en aquellos terrenos que, por decisión de sus dueños, se sometieran al régimen forestal. En otras palabras, permitía prohibir cazar libremente en numerosos terrenos del país.

A pesar de que, como vimos en los ejemplos que señalamos a principio del artículo, la proclamación de la República trajo nuevas esperanzas que esperaban eliminar las restricciones que establecieron los citados regímenes forestales en el ejercicio de la caza, el nuevo régimen político no modificó las grandes líneas de la legislación cinegética promulgada durante las últimas décadas de la Monarquía y, por ejemplo, desde un primer momento otorgó las competencias para la vigilancia del "ejercicio de la caza y de la pesca" a la GNR, cuerpo de policía rural creado en 1911 para satisfacer "las reclamaciones de los pueblos por la falta de una policía rural que [...] les proteja las propiedades contra los frecuentes asaltos de vagabundos y malhechores, que saquean los frutos y damnifican los cultivos"23.

Es más, como señalamos, los primeros gobiernos republicanos culminaron el proceso legislativo que buscaba expandir los cotos privados de caza en perjuicio de las áreas de libre usufructo cinegético con la promulgación de la ley de caza de $1913^{24}$, que, a la sazón, fue la primera ley de caza promulgada en el país.

A grandes rasgos, por un lado, esta ley confirmaba las disposiciones sobre caza que se veían estableciendo tanto en los Códigos de Posturas, como el de Arraiolos, y también en los decretos que crearon el régimen forestal; pero, por otro, establecía nuevas medidas que restringían y/o dificultaban aún más la caza libre.

\footnotetext{
${ }^{22}$ Respectivamente en Diário do Governo, n 296, 31 de diciembre de 1901; n² 294, 30 de diciembre de 1903; y n 161, 21 de julio de 1905

23 Diário do Governo, $n^{0} 103,4$ de mayo de 1911, 1813

${ }^{24}$ Diário do Governo, nº 156, 7 de julio de 1913, 2511-2512.
} 
En primer lugar, la nueva ley sólo concedía el derecho a cazar a quienes tuvieran una licencia dispensada por las Cámaras Municipales (arts. 3 y 7), la cual era independiente a la licencia de armas (art. $7 \S 10^{\circ}$ ) y a la contribución industrial que gravaba la venta y reventa de piezas de caza (art. $7 \S 3^{\circ}$ ). Es decir, que, como se quejaba un periodista de A Folha do Sul, la superposición de diversas cargas fiscales (licencia de caza, licencia de armas, contribución industrial) "imposibilita a los pobres trabajadores rurales, en épocas invernales y de crisis de trabajo, entregarse al arte de la caza, donde encontraban tantas veces su sustento y el de su familia"25.

En segundo lugar, la ley de caza de 1913 no sólo buscaba perseguir el propio ejercicio de cazar furtivamente, sino también otras actividades ilegales relacionadas, como era a la compra-venta de caza (art. 28) y de artefactos ilegales para cazar (art. 29).

Por último, la ley ampliaba notablemente la red de empleados públicos y funcionarios que se encargarían de fiscalizar su cumplimiento (art. 24), permitiendo al estado vigilar múltiples actividades de la vida cotidiana:

"A fiscalização desta lei compete, em especial, às guardas fiscal e republicana, a
todas as autoridades e agentes de autoridades administrativas, judiciais, fiscais,
militares, rurais, florestais, aduaneiras, aos chefes de estações e empregados
ferro-viários, guardas especiais e aos sócios de todas as agremiações de
caçadores, legalmente constituídas, mediante a apresentação do seu bilhete de
identidade, e bem assim os médicos veterinários encarregados da fiscalização
sanitária nas delegações e postos aduaneiros, assim como aos empregados da
inspecção sanitária nos mercados, mercearias e casas de venda de alimentos
de origem animal, incumbe tambêm organizar os processos que serviram para
apreensão da caça, ordenando a sua imediata confiscação no caso dêsses
processos não serem permitidos por lei, dando parte à autoridade
competente" 6

En definitiva, vemos que, efectivamente, en los años del cambio de siglo se sucedió en Portugal una intensa actividad legislativa para controlar y limitar el ejercicio libre de la caza. No obstante, a pesar de esta ofensiva legislativa, muchos campesinos del Alentejo se resistieron a dejar de cazar, aunque para ello tuvieran que infringir la ley, ya que, como veremos de inmediato, la caza era una actividad

${ }^{25}$ A Folha do Sul, 30 de agosto de 1913, 1.

${ }^{26}$ Diário do Governo, n 156, 7 de julio de 1913, 2512. 
indispensable para complementar sus economías domésticas de subsistencia, especialmente en períodos de falta de trabajo.

\section{LA CAZA FURTIVA EN EL DISTRITO DE ÉVORA A INICIOS DEL SIGLO XX}

Como apuntamos en su momento, varios autores portugueses han señalado que la caza, y dentro de ella también la furtiva, fue una práctica generalizada entre las comunidades rurales del Alentejo a lo largo de la historia, desde la época medieval y moderna hasta la contemporaneidad ${ }^{27}$. En nuestro caso, la documentación manejada también nos muestra que la caza furtiva fue una actividad generalizada que trajo numerosos quebraderos de cabeza las autoridades, incluso después de promulgarse la ley de 1913.

En este sentido, por ejemplo, no fue extraño que los periódicos locales y regionales recogieran quejas sobre los abusos que cometían los cazadores ilegales. Así, por ejemplo, Notícias d'Évora se hacía eco en 1916 de "los grandes y constantes abusos que se están practicando en los campos de este concelho, donde, clandestinamente se caza, a pesar de estar en tiempo de veda y donde los tramperos de perdices están haciendo abundante cosecha de estas aves y de otras que el calor fuerza a ir a saciar la sed a las fuentes y riachuelos" ${ }^{28}$. Por aquellos mismos días, otro periódico de Évora denunciaba que "tanto en el arroyo del Vinagre como en el de ValVerde y otros, los armazones para atrapar perdices a red son enormes"29. A los periódicos eborenses también llegaban quejas sobre los abusos de los cazadores furtivos desde otros concelhos del distrito, como Viana do Alentejo, donde en agosto de 1915 se denunciaba que "hay individuos que hace más de un mes se emplean en devastar toda clase de caza, bien por medio de escopeta, a salto, a la espera o lazo" ${ }^{\text {30. }}$

En la prensa local del vecino concelho de Montemor-o-Novo también se publicaron numerosas protestas sobre la generalización de la caza furtiva. Democracia

\footnotetext{
${ }^{27}$ Carmo, O problema da caça no Alentejo, 21-29; Fonseca, O Montado no Alentejo, 112-114.

${ }^{28}$ Notícias d'Évora, 11 de agosto de 1916, 2.

${ }^{29}$ A Voz Pública, 10 de agosto de 1916, 1.

30 Notícias d'Évora, 14 de agosto de 1915, 2.
} 
do Sul denunciaba en 1912 que "diariamente se ven individuos infringiendo el reglamento de veda, cazando animales que están al abrigo de aquella ley, destruyendo las creaciones por medio de trampas prohibidas, etc." 31 . Y, un año más tarde, A Folha do Sul noticiaba que las autoridades concejiles tuvieron que ordenar el envío de patrullas de la GNR a caballo a Cortiçadas de Lavre "por constar que allí sería infringida la nueva ley de caza" ${ }^{32}$.

Más allá de la prensa, también hemos podido recoger numerosas quejas y reclamaciones sobre los abusos de los cazadores furtivos en la documentación del Gobierno Civil. Por ejemplo, en 1913, el gobernador civil de Évora rogaba "con toda la insistencia" al comandante del batallón de la GNR de la ciudad "se digne recomendar a sus subordinados la mayor vigilancia sobre el riguroso cumplimiento de la ley sobre el ejercicio de la caza, deteniéndose al que fuera encontrado, para ser entregado, y buscándose por todos los medios entregar en juicio a los transgresores" 33 . Pocos días más tarde, a requerimiento de una carta del Club de los Cazadores Portugueses "sobre transgresión del ejercicio de la caza" en Montemor-o-Novo, el propio gobernador civil envió un oficio al Administrador de dicho concelho donde le instaba a "dar inmediatas providencias sobre este asunto" 34 . Al año siguiente, sería el ministro de Interior quien recomendó al gobernador civil de Évora "tome las providencias rigurosas para ser observadas y cumplidas las posturas tanto distritales como municipales que prohíben la caza en los meses de veda, procediendo contra los transgresores e incautando la caza que fuera expuesta a la venta o encontrada en posesión de los infractores" 35 . Y es que, por aquellos años, el problema de la caza furtiva, y concretamente el incumplimiento de las disposiciones establecidas en la ley de 1913, era un problema que afectaba no sólo a la región del Alentejo, sino también y especialmente a los distritos del norte del país, como bien muestra una circular que envió el ministerio de Interior a los gobernadores civiles del país en mayo de 1914:

\footnotetext{
${ }^{31}$ Democracia do Sul, 3 de agosto de 1912, 2.

${ }^{32}$ A Folha do Sul, 27 de agosto de 1913, 2.

${ }^{33}$ Oficio n. ${ }^{\circ}$ 445, 16 de agosto de 1912, Fondo Gobierno Civil, E/Correspondencia, Copiadores/3a Repartición, Caja n. ${ }^{\circ}$ 14, Libro n. ${ }^{\circ}$ 15, ADE.

34 Oficio n. ${ }^{\circ} 452,19$ de agosto de 1912, Fondo Gobierno Civil, E/Correspondencia, Copiadores/3a Repartición, Caja n. ${ }^{\circ}$ 14, Libro n. ${ }^{\circ} 15$, ADE.

${ }^{35}$ Circular n. ${ }^{\circ}$ 256, 22 de marzo de 1913, Fondo Gobierno Civil, Circulares, Caja n. ${ }^{0}$ 14, Libro n. ${ }^{0}$, ADE.
} 
"Tendo chegado ao conhecimento deste Ministerio que em muitos dos concelhos do pais, especialmente nos do norte, não tem sido cumprida rigorosamente a lei $\mathrm{n}^{\circ} 15$ de 7 de julho do anno findo, com manifesto prejuizo por algumas das suas disposições que muito taxativamente chamam à responsabilidade os seus contraventores; me encarrega o $\mathrm{Ex}^{\mathrm{mo}}$. Ministro do Interior de communicar a V. Exa . esta circunstancia, que por sua vez a transmitirá às auctoridades administrativas suas subordinadas, fazendo-lhes sentir a necessidade de fazer reprimir os abusos que por ventura neste sentido sejam practicados por individuos que não posuem os requisitos legaes para se entregarem ao exercicio da caça ou por aquelles que embora reconhecida a sua qualidade de caçadores nos termos da citada não à acatam em todos os seus detalhes"36

A raíz de los testimonios señalados podemos decir que, efectivamente, la caza furtiva fue una práctica generalizada en la región del Alentejo durante los primeros años de la I República. Con todo, a través de esta misma documentación también podemos conocer otras características de esta práctica, en especial, que fue un instrumento esencial utilizado por las clases populares para obtener recursos económicos.

En efecto, como se ha señalado en su momento, los cazadores furtivos se podían diferenciar entre quienes cazaban para buscar alimento y los que lo hacían sin tener esa necesidad básica ${ }^{37}$. En este sentido, en no pocas ocasiones la prensa del distrito de Évora de inicios del siglo XX muestra que muchos cazadores furtivos eran pobres campesinos que cazaban por necesidad. Ya hemos visto en el epígrafe anterior cómo desde A Folha do Sul se denunciaba que la superposición de diversas cargas fiscales "imposibilita a los pobres trabajadores rurales, en épocas invernales y de crisis de trabajo, entregarse al arte de la caza, donde encontraban tantas veces su sustento y el de su familia" 38 , hasta llegar al punto de que "¡un pobre cazador, sólo para ir a la caza de un conejo, tiene que pagar casi 4 escudos!"39. Quejas similares fueron recogidas por O Carbonário, quien además especificaba que "hay mucha gente que caza por lujo y por diversión pero también hay otros, y ésos la mayor parte, que cazan para ganarse la vida, y éstos ya son sobrecargados allí con la licencia de porte de

\footnotetext{
${ }^{36}$ Circular n. ${ }^{0}$ 50, 18 de mayo de 1914, Fondo Gobierno Civil, Circulares, Caja n. ${ }^{0} 14$, Libro n. ${ }^{\circ}$, ADE.

${ }^{37}$ Carmo, O problema da caça no Alentejo, 153.

38 Véase supra.

${ }^{39}$ A Folha do Sul, 3 de septiembre de 1913, 2.
} 
armas $^{\prime \prime 40}$. En una ocasión, incluso, el diario Notícias d'Évora recogió los testimonios de dos cazadores furtivos detenidos por la GNR, los cuales decían ser trabajadores rurales y reconocían que habían transgredido la ley de caza, aunque justificaban su acción "debido a los pocos recursos de que disponen, no tienen actualmente trabajo y desean tener de comer para dar a sus familias" ${ }^{\prime 41}$.

Es más, del mismo modo que ocurría con otros delitos rurales generalizados en el Alentejo, como el robo de frutos del campo ${ }^{42}$, la caza furtiva formaba parte de un amplio mercado negro que permitía a las clases más desfavorecidas de la región, en especial a los trabajadores rurales, obtener unos recursos monetarios para completar su precaria economía familiar en épocas de falta de trabajo, como vimos que eran los meses de otoño e invierno. Así por ejemplo, no era raro que en Évora aparecieran frecuentemente "a la venta por las calles y en el Mercado de esta ciudad manojos de pájaros, e incluso otros en jaulas, que no presentan el menor vestigio de haber sido cazados a tiro e incluso se muestra claramente que ellos fueron atrapados con redes, trampas, etc." ${ }^{43}$. Estos hechos explican mejor la razón de ser de los artículos 28 y 29 de la ley de caza de 1913, los cuales, como vimos, perseguían la compra-venta de presas cazadas ilegalmente, así como de cualquier tipo de trampa o artefacto de caza prohibido $^{44}$.

Con todo, como han señalado algunos autores, cabe tener en cuenta que los delitos rurales que cometían los individuos de las clases más pobres eran aceptados social y culturalmente por la mayor parte de la sociedad alentejana ${ }^{45}$. Por ello no es raro ver cómo las autoridades, y dentro de ellas especialmente las locales, mostraran cierta laxitud a la hora de perseguir a estos pequeños delincuentes, lo que provocaba las quejas de individuos pertenecientes a sectores sociales más acomodados, principalmente los propietarios de los grandes latifundios que caracterizan el paisaje

\footnotetext{
40 O Carbonário, 1 de septiembre de 1912, 1.

${ }^{41}$ Notícias d'Évora, 13 de agosto de 1915, 2; y 14 de agosto de 1915, 2.

42 Como señaló un gobernador civil de Évora: «Hay épocas en que, por la falta de servicios en el campo, los salarios son exiguos y por ese hecho la mayoría de la gente del campo prefiere robar los frutos pendientes, pues así consiguen, por haber quien le compre los robos por bien poco, sacar un rendimiento mayor del que el salario de su trabajo», Oficio n. ${ }^{\circ}$ 366, 27 de diciembre de 1910, Fondo Gobierno Civil, E/Correspondencia, Copiadores/3a Repartición, Caja n. ${ }^{0} 14-A$, Libro n. ${ }^{\circ} 14$, ADE.

${ }^{43}$ Oficio n. ${ }^{\circ}$ 255, 15 de julio de 1909, Fondo Gobierno Civil, E/Correspondencia, Copiadores/3a Repartición, Caja n. ${ }^{0}$ 14, Libro n. ${ }^{0}$ 13, ADE.

${ }^{44}$ Véase supra.

${ }^{45}$ Cutileiro, Ricos e pobres, 95-97; José P. Pereira, "As lutas sociais", 152.
} 
del Alentejo. Es lo que sucedió en Portel, donde "los 40 mayores contribuyentes y la mayoría de los propietarios" se quejaron ante el gobernador civil porque el juez del concelho "no se presta al juicio de las transgresiones de las ordenanzas [municipales]" por lo que existían en el juzgado "procesos parados hace 3 años"46. Otro ejemplo similar tuvo lugar en Borba, cuyo administrador fue recriminado por el gobernador civil porque liberó sin mayores formalidades a diversos individuos que habían cometido pequeños delitos rurales, entre ellos, "un individuo al que la misma guardia [nacional republicana] confiscó seis trampas cuando cazaban" 47 . A pesar de estas quejas, en numerosas ocasiones las autoridades locales alentejanas continuaron haciendo la vista gorda ante toda esa gama de pequeños delitos rurales que tenían como objetivo la supervivencia familiar, ya que, oponerse a la "economía moral" de la multitud, podía provocar la hostilidad y reacciones violentas del vecindario, como por ejemplo, el estallido de motines ${ }^{48}$. Es lo que ocurrió en Móra en septiembre de 1912. La tarde del día 5 del citado mes, el comandante del puesto de la GNR del concelho interceptó a un joven que estaba cazando sin la correspondiente licencia. Cuando el mozo intentó huir, el agente le disparó, hiriéndole en el hipocondrio, por lo que tuvo que ser trasladado al hospital de la villa. Cuando el vecindario se enteró de la desproporcionada reacción del guardia, "se amotinó, dirigiéndose para el puesto de la Guardia Republicana, viéndose su comandante en la necesidad de telegrafiar para Évora, pidiendo refuerzos y una investigación de sus actos" ${ }^{\$ 9}$.

Resumiendo, la prensa y documentación de las autoridades distritales muestra que la caza furtiva era una actividad generalizada en la sociedad alentejana de principios del siglo XX la cual tenía una clara función socioeconómica: dotar de unos recursos complementarios a las economías familiares de subsistencia de las clases populares. Por este último motivo, la caza furtiva, igual que otros pequeños delitos rurales, fue una actividad ilegal aceptada y tolerada por buena parte de la comunidad.

\footnotetext{
${ }^{46}$ Minuta n. ${ }^{0}$ 193, 17 de junio de 1909 y Minuta n. ${ }^{\circ} 329,25$ de noviembre de 1909, Fondo Gobierno Civil, E/Correspondencia, Copiadores $/ 1^{\mathrm{a}}$ Repartición, Caja n. ${ }^{\circ} 23$, Libro n. ${ }^{\circ} 14$, ADE.

47 Oficio n. ${ }^{\circ}$ 514, 26 de diciembre de 1913, Fondo Gobierno Civil, E/Correspondencia, Copiadores/3a Repartición, Caja n. ${ }^{\circ}$ 14-A, Libro n. ${ }^{0} 16$, ADE.

${ }^{48}$ Edward P. Thompson, "La economía «moral» de la multitud en la Inglaterra del siglo XVIII", en Edward P. Thompson, Tradición, revuelta y consciencia de clase. Estudios sobre la crisis de la sociedad preindustrial (Barcelona: Crítica, 1979), 62-134.

${ }^{49}$ Notícias d'Évora, 17 de septiembre de 1912, 2; y A Voz Pública, 19 de septiembre de 1912, 3. También en Oficio n. ${ }^{\circ} 498,15$ de septiembre de 1912, Fondo Gobierno Civil, E/Correspondencia, Copiadores/3a Repartición, Caja n. ${ }^{0} 14$, Libro n. ${ }^{\circ} 15$, ADE.
} 
No obstante, para conocer más detalles sobre la naturaleza de la caza furtiva, es necesario descender hasta una escala de análisis local. Para ello, en nuestro caso, hemos escogido el concelho de Arraiolos.

\section{LA CAZA FURTIVA EN EL CONCELHO DE ARRAIOLOS ENTRE 1910 y 1917}

Arraiolos es una villa del distrito de Évora que se sitúa a poco más de veinte kilómetros al norte de la capital distrital. En 1911 contaba con alrededor de 3000 habitantes. A pesar de su pequeño tamaño, la villa de Arraiolos era cabeza de un concelho que integraba otras localidades de menor tamaño (Igrejinha, Vimieiro, Santana do Campo, Gafanhoeira, Santa Justa, São Gregório, Vidigão) donde, en conjunto, habitaban unas 10.000 personas $^{50}$. Del mismo modo que ocurría con el resto de la región, la economía del concelho se basaba casi por completo en la agricultura ${ }^{51}$, ya que incluso la tradicional producción artesanal de las famosísimas alfombras de Arraiolos estaba en decadencia desde finales del siglo XIX ${ }^{52}$. En definitiva, cuando se proclamó la República, Arraiolos era un típico concelho rural y agrícola del Alentejo.

La elección de esta villa frente a otras de la región para realizar un análisis a escala local de la caza furtiva en el Alentejo de inicios del siglo XX se debe, simplemente, a que sobre Arraiolos hemos podido consultar tanto el Código de Posturas Municipales (que analizamos en el punto 1 de este texto), como también toda una serie completa de los juicios por transgresiones que se abrieron en el juzgado comarcal entre los años 1910 y 1917, entre los que se incluían los procesos por transgredir las legislaciones relativas al ejercicio de la caza.

En total, en el juzgado comarcal de Arraiolos se abrieron 44 procesos por caza ilegal, siendo la segunda causa que motivó más procesos tras la invasión de ganados en terrenos ajenos (68 procesos). Lo primero que destaca al analizar los procesos judiciales abiertos por caza ilegal es la fecha en que cometieron las infracciones y la

\footnotetext{
50 Censo da População de Portugal, 108-109.

${ }^{51}$ Hélder A. Fonseca, "Agricultura, especialización y diversificación productiva: la experiencia portuguesa en la «Región del Latifundio», 1850-

1910. Una interpretación", Noticiario de Historia Agraria, 9 (1995): $13-41$.

52 Bruno Lopes, Contributos para a História dos Tapetes de Arraiolos (Lisboa: Terramar, 2009), 31-36.
} 
condición socioprofesional de los infractores. Ambos aspectos nos aporta información esencial para comprender la naturaleza de la caza furtiva en el concelho.

Por lo que se refiere a la fecha, la inmensa mayoría de las infracciones se datan en meses de otoño (7 en septiembre, 6 en octubre, 5 en noviembre) y, específicamente, durante el mes de diciembre (22 procesos). Esto es, la mayoría de las infracciones se cometían cuando llegaban las lluvias otoñales y el frío invernal y, como consecuencia, se paralizaban las labores agrícolas en la región, lo cual, como advertimos, producía una escasez de demanda de mano de obra que ocasionaba un aumento estacional del desempleo y, en los años más severos, acusadas crisis de trabajo que, no pocas veces, como ya hemos apuntado, obligaban a muchos individuos a acudir a la pequeña delincuencia para sobrevivir.

Otra información ilustrativa es la condición socioprofesional de los acusados. De los 50 procesados de los que la documentación nos señala su oficio, 34 eran trabajadores rurales, esto es, formaban parte de uno de los sectores sociales más desfavorecidos de la sociedad portuguesa. Más allá de éstos, encontramos otros individuos que también formaban parte de las clases populares, como eran zapateros, obreros ferroviarios o un antiguo agente de la GNR.

En definitiva, el análisis de los procesos judiciales por caza ilegal abiertos en el juzgado comarcal de Arraiolos nos confirma que, como vimos en el punto 2 a través de la prensa y la correspondencia de las autoridades distritales, buena parte de la caza furtiva ejercida en el Alentejo durante los primeros años del siglo XX era ejecutada por individuos de las clases más bajas quienes buscaban obtener algunos recursos complementarios para sus vulnerables economías familiares.

No obstante, más allá de certificar lo que ya vimos en el punto anterior, la documentación del tribunal comarcal de Arraiolos nos permite obtener nueva información que nos ayuda a entender la esencia de la caza furtiva en la región estudiada.

Por ejemplo, es sumamente interesante analizar los lugares del concelho donde se cometieron las infracciones sobre caza furtiva. En el caso concreto de Arraiolos, la 
mayor parte de las denuncias que originaron los procesos juzgados en el tribunal comarcal fueron interpuestas por los guardas forestales de dos parajes: la Mata de Val de Flores y la Herdade da Mata (véase Mapa 2).

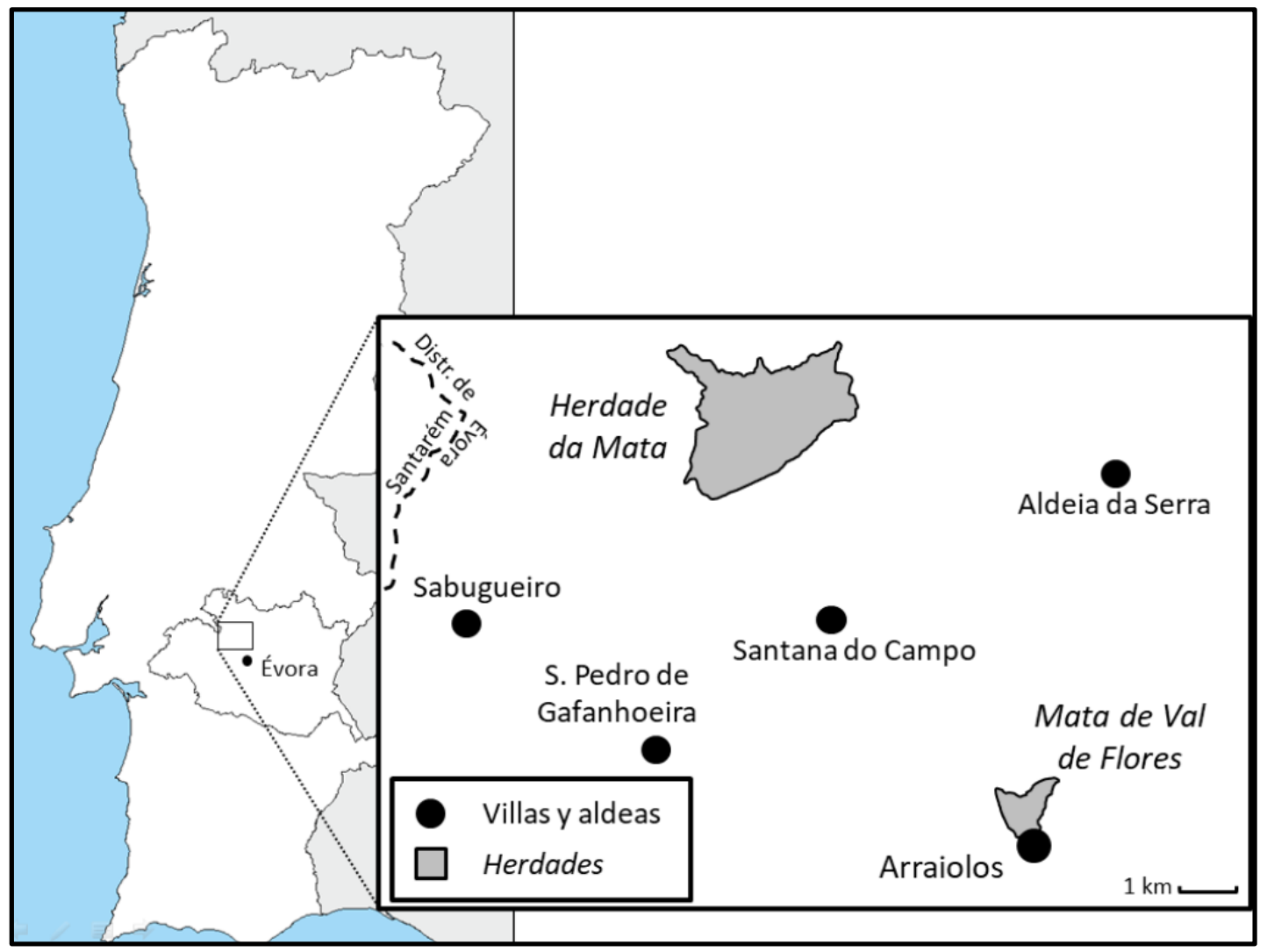

Mapa 2. Localización de la Mata de Val de Flores y la Herdade da Mata dentro del concelho de FUENTE: Elaboración propia Arraiolos

La Mata de Val de Flores es un paraje que se sitúa a las afueras de la propia villa de Arraiolos, en donde se erige el edificio del antiguo Convento de Nuestra Señora de la Asunción, expropiado a raíz de la desamortización eclesiástica iniciada en 1834 . Según consta en algunas de las denuncias consultadas, los terrenos habían sido sometidos al régimen forestal en diciembre de 1911, lo que suponía que, como vimos en el apartado 1, pasaban de ser un lugar donde se podía ejercer libremente la caza (siempre que se respetaran las ordenanzas municipales) a convertirse en un coto privado. Sin embargo, esta restricción no supuso que los trabajadores rurales de los alrededores se resignaran a no disfrutar de un recurso natural (como la caza) que era básico para la subsistencia familiar y que, hasta entonces, la ley no les había prohibido 
usufructuar. Todo lo contrario, como muestra los 15 procesos abiertos por caza ilegal en el lugar, dichos trabajadores no dudaron en seguir cazando en la Mata de Val de Flores, aunque ello supusiera tener que quebrantar la ley. Es el caso de António José Branco, un vecino de Arraiolos, que la documentación señala como zapatero y trabajador, el cual fue denunciado en tres ocasiones por estar cazando de forma ilegal en la citada heredad. La primera denuncia data de septiembre de 1913, cuando António José fue sorprendido, junto a otros cinco vecinos de Arraiolos (dos negociantes y tres trabajadores), "con armas de fuego fuera de los caminos usuales y desbastados transgrediendo el [...] Reglamento de Policía Forestal". Ante las acusaciones, uno de los denunciados, de nombre Julio Bastos Rietim, respondió: "Que era verdad haber cometido la transgresión a la que los autos se refieren, pero si así procedió fue porque ya el año pasado habiendo cazado en la heredad de Val de Flores, nadie se le opuso, juzgando por eso que lo mismo podría hacer este año"53. En el mismo mes de septiembre de 1914, pocos días más tarde de los hechos que acabamos de reseñar, tanto António José Branco como Julio Bastos Rietim volvieron a ser sorprendidos en la Mata de Val de Flores "con armas de fuego fuera de los caminos usuales y desbastados, transgrediendo el [...] Reglamento de Policía Forestal"54. A pesar de los dos precedentes, António José Branco no se resignó a dejar de cazar en la heredad, y en octubre de 1915 fue de nuevo denunciado, junto a otros dos vecinos de Arraiolos, por estar "fuera de los caminos usuales y desbastados con arma de fuego"

Otro ejemplo ilustrativo es el de Leonardo Clemente, un trabajador rural de Arraiolos el cual también fue sorprendido en la Mata de Val de Flores en septiembre de 1914 "con armas de fuego, fuera de los caminos usuales y desbastados" esta primera denuncia, Leonardo reincidió. En septiembre de 1916 fue denunciado por estar "fuera de caminos usuales y desbastados con arma de fuego" en la Mata de Lourinha (otro paraje el concelho de Arraiolos) ${ }^{57}$; y, al año siguiente, en septiembre de 1917, por transitar nuevamente por la Mata de Val de Flores "fuera de los caminos

\footnotetext{
53 Proceso n. ${ }^{0} 2387,1$ de septiembre de 1914, Fondo Tribunal de Comarca de Arraiolos, Procesos criminales, Legajo n. ${ }^{\circ} 68$, ADE. 54 Proceso n. ${ }^{\circ} 2360,7$ de septiembre de 1914, Fondo Tribunal de Comarca de Arraiolos, Procesos criminales, Legajo n. ${ }^{\circ} 68$, ADE ${ }^{55}$ Proceso n. ${ }^{\circ} 2393,5$ de octubre de 1915, Fondo Tribunal de Comarca de Arraiolos, Procesos criminales, Legajo n. ${ }^{\circ} 68$, ADE.

${ }^{56}$ Proceso n. ${ }^{\circ}$ 2375, 5 de septiembre de 1914, Fondo Tribunal de Comarca de Arraiolos, Procesos criminales, Legajo n. ${ }^{\circ} 68$, ADE.

57 Proceso n. ${ }^{\circ}$ 2451, 22 de septiembre de 1916, Fondo Tribunal de Comarca de Arraiolos, Procesos criminales, Legajo n. ${ }^{\circ} 69$, ADE.
} 
usuales y desbastados con arma de fuego" ${ }^{25}$. En esta última ocasión, la absolución del procesado levantó las quejas del propietario que, como podemos ver, sufría reiteradas incursiones de cazadores furtivos en los terrenos su propiedad:

"Mais uma vez o meretissimo Juiz d'esta comarca absolveu um transgresor do regulamento de policia florestal, embora essa transgressão estivesse absolutamente provada e não fosse a primeira vez que a cometia [...]. Umas vezes absolve sua Ex. ${ }^{a}$ os reos d'este mesmo delicto porque há apenas uma testemunha, outras porque eles mentindo, dizem que foram beber agua e ainda outras porque, mentindo da mesma forma, dizem terem ido dentro da propriedade buscar uma peça de caça que ferida por elles, ali foi parar" ${ }^{\not 59}$

La Herdade da Mata, por su parte, era un terreno de más de mil quinientas hectáreas, buena parte de ellas de montado (dehesa), que se sitúa al norte de la aldea de Santana do Campo. En aquellos años, la heredad pertenecía a António Rosado Mexia Dórdio, un rico labrador local que fue vicepresidente de la última corporación municipal monárquica de $\operatorname{Arraiolos}^{60}$. Como sucedió con el ejemplo anterior, el propietario acogió a la Herdade da Mata al régimen forestal en enero de 1909, convirtiendo el lugar en un coto privado de caza. Nuevamente, la prohibición no impidió que, durante los meses siguientes, la Herdade da Mata fuera el paraje del concelho de Arraiolos más concurrido por los cazadores furtivos que vivían en las aldeas de su entorno, tanto en Santana do Campo, como en São Pedro de Gafanhoeira, Sabugueiro o Aldeia da Serra. Es el caso de los doce protagonistas del relato que encabeza este artículo, los cuales aprovecharon el desconcierto que siguió a la proclamación de la República para quebrantar las leyes que prohibían cazar en aquella heredad. No fueron los únicos, ya que entre los años 1910 y 1913 se abrieron otros 23 procesos por caza ilegal en la Herdade da Mata, la mayoría ejecutados por trabajadores rurales. Por ejemplo, el 29 de octubre de 1913, el guarda de la heredad interceptó, "fuera de los caminos usuales y desbastados con arma de fuego", a cuatro

\footnotetext{
58 Proceso n. ${ }^{0} 2477,9$ de septiembre de 1917, Fondo Tribunal de Comarca de Arraiolos, Procesos criminales, Legajo n. ${ }^{\circ} 69$, ADE.

59 Ibídem.

60 «Acta da posse da Commissão Municipal da República Portuguesa. Aos nove dias do mez d'Outubro do anno do mil novecentos e dez, nesta villa d'Arrayollos e na sala das sessões da Cámara Municipal nos Paços do Concelho, em que se achavam presentes pelo meio dia o VicePresidente da mesma Cámara, António Rosado Mexia Dórdio, e vereadores da referida cámara, assim como Manuel Amaral de Mira, Administrador do Concelho substituto; a bem mais José de Mira Amaral, Jeronymo Queiroga, Joaquim Ignacio Calahu, Jose Mexia de Brito Rosado e Augusto Henrique da Costa Simões, que apresentaram as suas nomeações feitas pelo Exmo. Governador Civil deste districto para vogaes da Commissão Municipal republicana deste concelho, que há de funcionar até que por eleição seja substituida». Acta n. ${ }^{\circ} 1,9$ de octubre de 1910, Fondo Cámara Municipal de Arraiolos, B/ Órgano del Municipio, Libros de actas de la corporación municipal, Libro n. ${ }^{\circ} 74$, Archivo Municipal de Arraiolos. La cursiva es nuestra.
} 
trabajadores de Sabugueiro: los hermanos Francisco y Joaquim António Tirapicos, Agostinho Mira y José Francisco Forca ${ }^{61}$. Los cuatro eran bien conocidos por el guarda del lugar. Por un lado, los hermanos Tirapicos eran dos de los individuos que formaban parte del grupo de doce cazadores que invadió la Herdade da Mata en octubre de 1910. Por su parte, Agostinho Mira, también había sido denunciado anteriormente, concretamente en diciembre de 1912, "acusado del delito de cazar sin licencia en la Herdade da Mata sujeto al Régimen Forestal"62. A pesar de todos estos antecedentes, los cuatro procesados serían nuevamente denunciados el 8 de noviembre de 1913 por encontrarse en la misma Herdade da Mata "con armas de fuego, fuera de los caminos públicos, usuales y desbastados" ${ }^{\prime 63}$. En esta ocasión, la documentación del proceso abierto en el tribunal comarcal de Arraiolos recoge los testimonios de los procesados. De este modo, al ser preguntados si cometieron la transgresión de que eran acusados, José Francisco Forca respondió "que era verdad haber cometido la transgresión [...] pero que si procedió así, fue porque le habían dicho que la herdade da Mata no estaba en las condiciones que la ley exige"; Agostinho de Mira alegó "que era verdad haber cometido la transgresión [...] pero que si la practicó fue porque le dijeron que a la puerta de la Iglesia de San Pedro, había fijado un edicto diciendo que estaba permitido cazar en la herdade da Mata"; y, por último, Joaquim António Tirapicos, dijo "que era verdad haber practicado la transgresión que le es imputada, pero si así procedió, fue por ignorar que estaba prohibido cazar en la herdade da Mata". Como es obvio, y conociendo sus antecedentes, nadie se puede creer que los tres no supieran que no se podía cazar en el lugar. Sin duda, estaban mintiendo... pero la ignorancia fingida era una de las características propias de las formas cotidianas de resistencia campesina ${ }^{64}$, en nuestro caso concreto, la resistencia a perder el usufructo de un recurso natural, como era la caza, que, como hemos visto, era esencial para complementar las economías familiares de subsistencias de las clases populares del Alentejo.

\footnotetext{
61 Proceso n. ${ }^{\circ}$ 2386, 29 de octubre de 1913, Fondo Tribunal de Comarca de Arraiolos, Procesos criminales, Legajo n. ${ }^{\circ} 68$, ADE. 62 Proceso n. ${ }^{\circ}$ 2347, 10 de enero de 1913, Fondo Tribunal de Comarca de Arraiolos, Procesos criminales, Legajo n. ${ }^{\circ}$ 67, ADE.

${ }^{63}$ Proceso n. ${ }^{\circ} 2359,8$ de noviembre de 1913, Fondo Tribunal de Comarca de Arraiolos, Procesos criminales, Legajo n. ${ }^{\circ} 67$, ADE.

${ }^{64}$ Scott, "Formas cotidianas", 14.
} 


\section{CONCLUSIONES}

A lo largo del texto hemos podido ver cómo en las comunidades rurales alentejanas de inicios del siglo XX hubo una notable resistencia a perder el libre usufructo de un recurso natural, como era la caza, cuya actividad fue progresivamente restringida y privatizada por el estado portugués. Para ello hemos tomado el ejemplo del distrito de Évora y, dentro del mismo, del concelho de Arraiolos, durante los años 1910 y 1917.

En primer lugar hemos podido ver que, efectivamente, durante ese período la legislación portuguesa reguló a distintos niveles la caza, buscando obstaculizar y, en último término, prohibir, el libre ejercicio de la misma. Primeramente, a finales del siglo XIX, la actividad cinegética fue regulada por la administración local a través los Códigos de Posturas Municipales. En el caso concreto de Arraiolos, la caza no sólo fue regulada por el Código promulgado en 1892, sino que la única reforma que sufrió el mismo, publicada en 1897, se dedicó exclusivamente a interponer más obstáculos y prohibiciones a su práctica. Más tarde, en los primeros años del siglo XX, las competencias para legislar la caza fueron asumidas por el estado, quien incidió en la promulgación de medidas que restringían su libre ejercicio, primero, mediante la creación del régimen forestal establecido por los decretos de 1901, 1903 y 1905, los cuales permitieron crear cotos privados de caza; y, segundo, ya en época republicana, con la promulgación de la ley de caza de 1913.

En segundo lugar, a través de la prensa regional y la documentación del gobierno civil hemos podido ver que, a pesar de la legislación restrictiva, los habitantes de las comunidades rurales del Alentejo continuaron practicando de forma generalizada la caza en los montes y heredades de la región, aunque ello supusiera hacerlo de forma furtiva. Es más, a través de dicha documentación también hemos podido saber que la caza ilegal era practicada mayormente por individuos que pertenecían a las clases más desfavorecidas (principalmente trabajadores rurales), quienes veían en esta actividad una forma de obtener unos recursos económicos complementarios para sus precarias economías domésticas. 
En tercer y último lugar, hemos descendido a una escala de análisis local utilizando la documentación del juzgado comarcal del concelho de Arraiolos. Esto no sólo nos ha permitido certificar que la caza furtiva era ejecutada mayoritariamente por trabajadores rurales con objeto de solventar carencias económicas en períodos de falta de trabajo (finales del otoño e inicios del invierno), sino que dicha actividad, se concentró en aquellos terrenos que, como consecuencia de la legislación promulgada a inicios del siglo XX, se convirtieron en cotos privados de caza y, por lo tanto, dejaron de ser espacios para el libre aprovechamiento de la caza.

\section{BIBLIOGRAFÍA}

Ana M. Cardoso, "A indústria no distrito de Évora, 1836-90", Análise Social, 112-113 (1991): 561-581.

Ana P. de Brito Pereira, "As greves rurais de 1911-1912: uma leitura através da imprensa", Análise Social, 77-78-79 (1983): 477-511.

Ana Fonseca, O Montado no Alentejo (Século XV a XVIII) (Lisboa: Colibri, 2004).

Bruno Lopes, Contributos para a História dos Tapetes de Arraiolos (Lisboa: Terramar, 2009).

Edward P. Thompson, Whigs and hunters: the origin of the Black Act (London: Allen Lane, 1975).

Edward P. Thompson, "La economía "moral" de la multitud en la Inglaterra del siglo XVIII", en Edward P. Thompson, Tradición, revuelta y consciencia de clase. Estudios sobre la crisis de la sociedad preindustrial (Barcelona: Crítica, 1979), 62-134.

Eric J. Hobsbawm y George Rudé, Revolución industrial y revuelta agraria. El Capitán Swing (Madrid: Siglo XXI, 1985).

Hélder A. Fonseca, "Agricultura, especialización y diversificación productiva: la experiencia portuguesa en la "Región del Latifundio", 1850-1910. Una interpretación", Noticiario de Historia Agraria, 9 (1995): 13-41.

Helder A. Fonseca, O Alentejo no século XIX. Economía e atitudes económicas (Lisboa: Imprensa Nacional Casa da Moeda, 1996).

James C. Scott, "Formas cotidianas de rebelión campesina", Historia Social, 28 (2018): 13-39. 
Jesús Ángel Redondo Cardeñoso, "Movilización y conflictos campesinos durante la crisis de la Monarquía y la instauración de la I República en Portugal: el Alentejo Central entre 1908 y 1914", Historia Social, 90 (2018): 23-43.

José Cutileiro, Ricos e pobres no Alentejo (Uma sociedade rural portuguesa) (Lisboa: Libraria Sá da Costa Editora, 1977).

José P. Pereira, "As lutas sociais dos trabalhadores alentejanos: do banditismo à greve", Análise Social, 61-62 (1980): 135-156.

José P. Pereira, Conflitos sociais nos campos do sul de Portugal (Mem Martins: Publicações Europa-América, 1983).

Manuel V. Cabral, "Situação do operariado nas vésperas da implantação da República", Análise Social, 112-113 (1977): 419-448.

Mário do Carmo, O problema da caça no Alentejo (1901-1975). Atitudes, expectativas e tensões sociais no distrito de Beja (Lisboa: Mário do Carmo, 2000).

Vasco P. Valente, O poder e o povo. A revolução de 1910 (Lisboa: Moares, 1982).

Fuentes

Prensa:

Diário do Governo (Lisboa, Portugal)

Notícias d'Évora (Évora, Portugal)

A Voz Pública (Évora, Portugal)

O Carbonário (Évora, Portugal)

Democracia do Sul (Montemor-o-Novo, Portugal)

A Folha do Sul (Montemor-o-Novo, Portugal)

Fondos archivísticos:

Fondo Gobierno Civil, E/Correspondencia, Archivo Distrital de Évora

Fondo Tribunal de Comarca de Arraiolos, Procesos criminales, Archivo Distrital de Évora 


\title{
Everyday resistances to the privatization of natural resources in Portugal in the early $20^{\text {th }}$ century: the example of poaching in the Alentejo region
}

\begin{abstract}
The article analyses the poaching in Portuguese rural communities during the early $20^{\text {th }}$ Century. To do this, the text takes as a frame of the study the Portuguese region of Alentejo between 1910 and 1917. The paper is divided into four parts: first, it makes a brief socioeconomic description of the region; second, it studies the hunting legislation; third, it analyses the poaching in the region by means of the information compiled in regional newspapers and regional government's files; and, fourth, it delves into the poaching nature through the judicial files from local court of Arraiolos. Our objective is to show that the poaching was a widespread practice that it was mainly used by the people of the working classes from the region to resist the laws that privatised and restricted the free exploitation of some essential natural resources for their subsistence domestic economies.
\end{abstract}

Key words: poaching, everyday resistances, peasants, rural communities, Alentejo 